\title{
Two new species of Rhabdias Stiles et Hassall, 1905 (Nematoda: Rhabdiasidae) from anuran amphibians in Pará, Brazil
}

\author{
Yuriy Kuzmin ${ }^{1}$, Francisco Tiago de Vasconcelos Melo $^{2}$, Heriberto Figueira da Silva Filho ${ }^{3}$ and \\ Jeannie Nascimento dos Santos ${ }^{2}$ \\ ${ }^{1}$ Department of Parasitology, I. I. Schmalhausen Institute of Zoology, Kyiv, Ukraine; \\ ${ }^{2}$ Laboratório de Biologia Celular e Helmintologia Prof ${ }^{a} \operatorname{Dr}^{\mathrm{a}}$ Reinalda Marisa Lanfredi, Instituto de Ciências Biológicas, Universidade \\ Federal do Pará, Belém, PA, Brazil; \\ ${ }^{3}$ Laboratorio de Zoologia e Ecologia de Vertebrados, Instituto de Ciências Biológicas, Universidade Federal do Pará, Belém, PA, \\ Brazil
}

\begin{abstract}
Two new lung-dwelling nematode species of the genus Rhabdias Stiles et Hassall, 1905 were discovered in Caxiuanã National Forest, Pará state, Brazil. Rhabdias galactonoti sp. n. was found in a dendrobatid frog Adelphobates galactonotus (Steindachner). The species is characterised by the regularly folded inner surface of the anterior part of the buccal capsule seen in apical view, flaskshaped oesophageal bulb and narrow, elongated tail. Rhabdias stenocephala sp. n. from two species of leptodactylid frogs, Leptodactylus pentadactylus (Laurenti) (type host) and L. paraensis (Heyer), is characterised by a narrow anterior end that is separated from the remaining body by a constriction. Both species possess six small but distinct lips, a cuticle that is inflated along the whole body, a doliiform buccal capsule separated into a longer anterior and a shallow, ring-shaped posterior part, lateral pores in the body cuticle and zones of spermatogenesis in the syngonia. Rhabdias galactonoti sp. $\mathrm{n}$. is the first species of the genus found in Dendrobatidae; R. stenocephala sp. n. is the second species described from Leptodactylidae in eastern Amazonia.
\end{abstract}

Keywords: taxonomy, Adelphobates, Leptodactylus, Rhabdiasidae, Anura, eastern Amazonia, South America

Parasitic nematodes of the genus Rhabdias Stiles et Hassall, 1905 inhabit the lungs of amphibians and some reptiles. The genus includes approximately 80 species occurring on all continents except Antarctica (Kuzmin and Tkach 2015). Fifteen nominal species are known from amphibian hosts in the Neotropical region: $R$. alabialis Kuzmin, Tkach et Brooks, 2007, R. androgyna Kloss, 1971, R. breviensis Nascimento, Gonçalves, Melo, Giese, Furtado et Santos, 2013, R. elegans Gutiérrez, 1945, $R$. fuelleborni Travassos, 1926, R. hermaphrodita Kloss, 1971, R. kuzmini Martínez-Salazar et León-Règagnon, 2007, R. manantlanensis Martínez-Salazar, 2008, R. mucronata Schuurmans Stekhoven, 1952, R. paraensis Santos, Melo, Nascimento, Nascimento, Giese et Furtado, 2011, R. peninsularis Martínez-Salazar, Falcón-Ordaz, González-Bernal, Parra-Olea et Pérez-Ponce de León, 2013, R. pseudosphaerocephala Kuzmin, Tkach et Brooks, 2007, R. savagei Bursey et Goldberg, 2005, R. tobagoensis Moravec et Kaiser, 1995, and $R$. truncata Schuurmans Stekhoven, 1952 (Kuzmin et al. 2015).
The life cycles of species of Rhabdias include a parasitic and a free-living phase; infective larvae dwell in host faeces and soil and enter the amphibian hosts via direct skin penetration (Baker 1979, Anderson 2000, Langford and Janovy 2009). Consequently, species of this genus are commonly parasitic in terrestrial and semi-aquatic amphibians.

During the joined herpetological and parasitological investigations in the Caxiuanã National Forest (Floresta Nacional de Caxiuanã) in Melgaço municipality, Pará, Brazil, we found various amphibian species harbouring lung nematodes, including Adelphobates galactonotus (Steindachner) (Dendrobatidae), Leptodactylus pentadactylus (Laurenti) and L. paraensis (Heyer) (Leptodactylidae).

After examination under a light microscope, the nematodes collected from A. galactonotus and Leptodactylus spp. were assigned to the genus Rhabdias, based on their morphology, infection site and parasitism in amphibians. They appeared to represent two morphological forms and each was found to be different from all known species of Rhabdias species. Therefore, we describe them herein as two new species of Rhabdias. 


\section{MATERIALS AND METHODS}

Amphibians were collected manually during day and night time excursions in Caxiuanã National Forest (Floresta Nacional de Caxiuanã), Melgaço municipality, Pará, Brazil, in February 2015. Collections were done under collection permit SISBIO (No. 30772-4) and IBAMA (No. 12420-2). Leptodactylus pentadactylus (4 specimens) and L. paraensis (11 specimens) were sampled from the same habitat close to the Caxiuanã Research Station. Specimens of A. galactonotus originated from two populations separated by the Caxiuanã Bay and belonged to 'orange' (12 specimens) and 'light blue' (6 specimens) colour morphs (after Hoogmoed and Avila-Pires 2012).

All host individuals were killed by injection of lidocaine hydrochloride $2 \%$ and their internal organs were examined under a dissecting stereomicroscope. Nematode individuals from the lungs were washed in $0.98 \%$ saline and fixed in heated $70 \%$ alcohol. Additionally, type specimens of $R$. tobagoensis (holotype and 2 paratypes; collection No. N-619) were borrowed from the Helminthological Collection of the Institute of Parasitology (České Budějovice, Czech Republic) and used for comparative studies. The type series of the two species described were each selected from a single host specimen.

Prior to examination under a light microscope, nematodes were cleared in lactophenol and mounted on temporary slides. Apical sections were made manually, using a razor blade and studied en face. Upon completion of our studies, nematodes were transferred to $70 \%$ alcohol for storage. Nematodes were examined under an Olympus BX41 microscope equipped with a drawing tube and an Olympus BX53 microscope equipped with differential interference contrast optics and a digital camera. All measurements were made using the Olympus imaging software cellSens Standard 1.9 (Olympus, Japan), and are presented in micrometres unless otherwise indicated. The classification of amphibian hosts follows that of Frost (2016) and de Sá et al. (2014).

\section{RESULTS}

\section{Rhabdias galactonoti sp. n.}

Figs. 1, 2

ZooBank number for species:

urn:Isid:zoobank.org:act:1614847C-92BC-4E1A-8642-42638715819C

Description. (Based on 5 type specimens, gravid hermaphrodites. Measurements of the holotype are followed by the ranges for the type series in parentheses. Measurements of the entire sample studied are given in Table 1.)

Body elongated, wider in mid-region, gradually tapering in anterior and posterior thirds (Fig. 2A). Anterior end rounded, posterior end pointed. Body length $6.04 \mathrm{~mm}$ (5.60-6.04 mm), width at vulva 263 (242-268), width at oesophago-intestinal junction 176 (144-176). Cuticle inflated along entire body, with transverse folds. Lateral pores and ducts distinct along body, ducts in shape of narrow funnels crossing inflated layer of cuticle (Fig. 2C).

Oral opening round (Fig. 1G). Six small lips present on apical surface. Submedian lips located close to edge of oral opening. Lateral lips smaller, located at some distance from oral opening. Each lip with prominent internal labial papilla on its inner edge; external labial papillae not ob- served. Amphidial openings located posterior to lateral lips (Fig. 1G). Vestibulum narrow, cuticularised, with folds on inner surface seen in apical view (Fig. 1H). Buccal capsule doliiform, widest at mid-depth, consisting of thickwalled anterior part and shallow, thin-walled posterior part (Fig. 1B). Anterior part transparent, circular in apical view, with regularly folded inner surface (Fig. 1I). Posterior part surrounded by apex of oesophagus, with 3 paired thickenings directed into lumen (Fig. 1J), tooth-shaped in lateral view (Fig. 1B), associated with borders between oesophageal sectors. Maximum diameter of buccal capsule 16 (14-17), total depth of both parts 12 (10-12); depth to width ratio $0.8(0.7-0.8)$.

Oesophagus club-shaped (Fig. 1A), 443 (419-459) long [7.3\% (7.3-8.1\%) of body length], with slight dilatation in middle of anterior half. Width of oesophagus anterior end 32 (27-32), maximum width of anterior dilatation 43 (39-43), width posterior to dilatation 37 (31-37). In posterior half, oesophagus gradually widening towards flaskshaped bulb; bulb with flattened posterior edge, 73 (61-73) wide. Nerve-ring encircling oesophagus posterior to its anterior dilatation, anterior to its mid-length (Fig. 1A), at 165 (165-184) from anterior end, this distance corresponding to $37 \%(37-43 \%)$ of oesophagus length. Excretory pore distinct in some specimens posterior to nerve ring (Fig. 1A), at 250 (195-250) from anterior end. Excretory duct narrow, straight. Excretory glands absent in gravid specimens. Intestine thick-walled, its anterior part much wider than oesophageal bulb, occupying entire space in pseudocoelome (Figs 1A, 2A). Rectum funnel-shaped, wide in anterior part, tapering posteriorly, prominently cuticularised (Fig. 1C).

Genital system amphidelphic, typical of the genus. Vulva usually pre-equatorial, situated at $2.8 \mathrm{~mm}(2.5-2.8 \mathrm{~mm})$ from anterior end [46\% (43-50\%) of body length]. Lips of vulva not salient (Fig. 2D). Vagina short, transverse, cuticularised. Uteri joined, thin-walled, containing numerous eggs ( $>100$ in total); eggs near vulva with fully-developed embryos. Egg size 103-114 × 57-63 $(\mathrm{N}=11$, measured in uteri of paratype). Both genital tubes U-bent in proximal parts of seminal receptacles. Distance from anterior end of body to anterior U-bend 1041 (593-1 155), distance from posterior U-bend to tail end 1077 (694-1 077). Testis zones observed in all specimens, in at least one syngonium (Fig. 2B). Numerous sperm cells usually observed in seminal receptacles (Fig. 2E). Proximal parts of syngonia overlapping level of vulva.

Tail narrow, gradually tapering (Fig. 1C). Slight elevation of body wall present on ventral side posterior to anus. In caudal region, cuticular inflation not reaching tail tip (Fig. 1C,F). Tail length 229 (229-333), or 3.8\% (3.8-6.0\%) of body length. Phasmids located at 91 (91-120) from tail end (Fig. 1F).

Immature specimens. One immature specimen (Fig. 1D,E) was found in the lungs of its host (orange morph). It differed from gravid specimens by the following characters: smaller size (body length $2.17 \mathrm{~mm}$ ), post-equatorial vulva (distance from anterior end to vulva corresponded to $53 \%$ of body length), absence of eggs in uteri, 


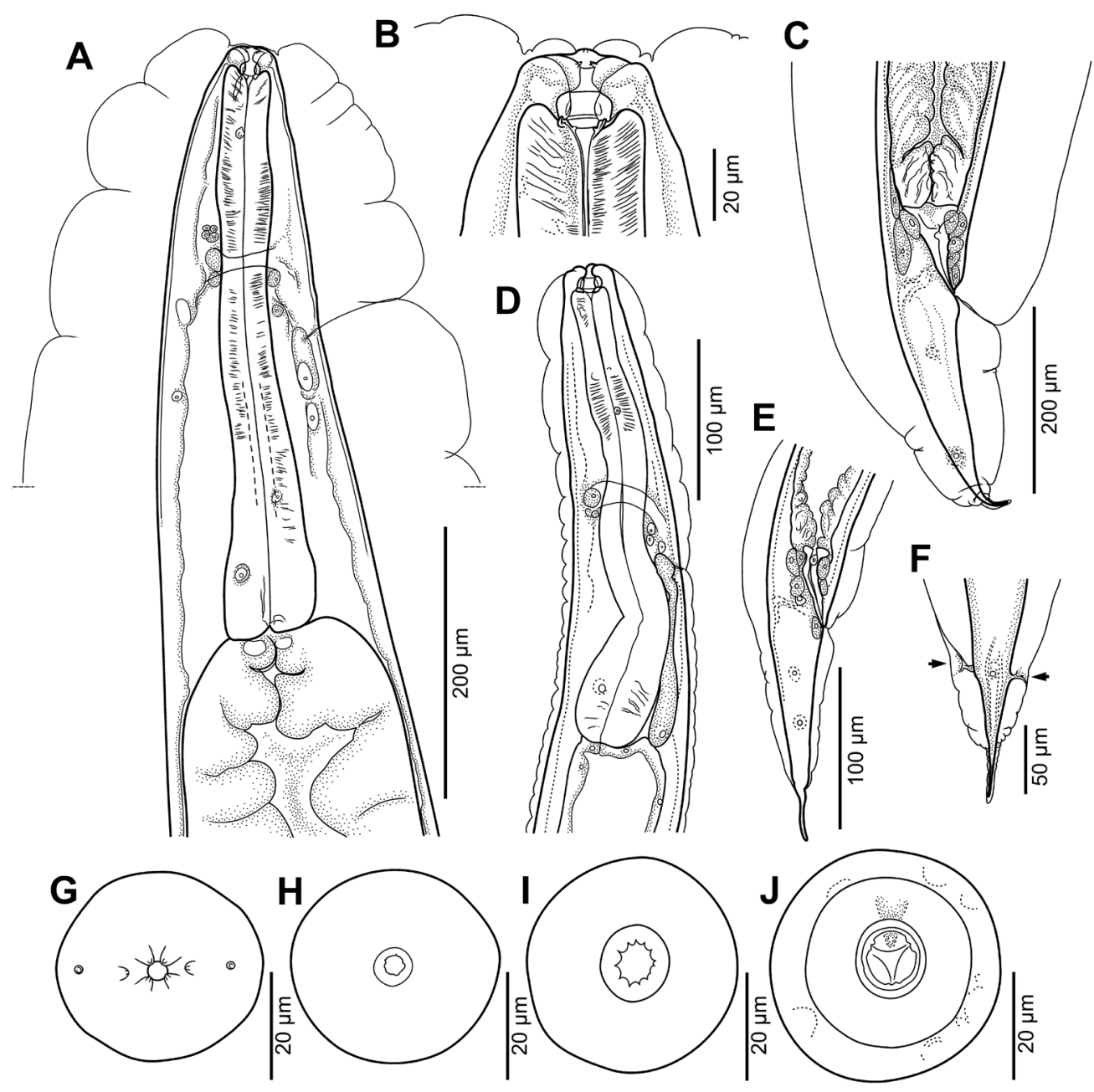

Fig. 1. Rhabdias galactonoti sp. n. from Adelphobates galactonotus (Steindachner), line drawings. A - anterior part of body, lateral view (holotype); B - anterior end, lateral view (holotype); C - posterior part of body, lateral view (holotype); D - immature specimen, anterior part of body, dorso-lateral view; $\mathbf{E}$ - immature specimen, posterior part of body, lateral view; $\mathbf{F}$ - caudal end, dorsal view (paratype), showing phasmids (arrowheads); G - anterior end of body, en face view; H - optical section through vestibulum; I - optical section through anterior part of buccal capsule; $\mathbf{J}$ - optical section through posterior part of buccal capsule.

less inflated body cuticle and presence of distinct excretory glands (Fig. 1D). Size of buccal capsule $(15 \times 9)$, as well as shape of oesophagus and tail (Fig. 1E) in immature specimen similar to those in gravid worms.

Variability. In the two samples of mature worms studied, the specimens collected from the blue colour morph of $A$. galactonotus were somewhat different from those from the orange colour morph (Table 1). In the former specimens body length and all related metrical characters (body width, oesophagus dimensions, tail length, distance to nerve ring, distance to vulva), as well as buccal capsule width exceeded those seen in the orange colour morph, whereas buccal capsule length was rather similar in the two samples. The qualitative characters, however, were found not to be different in the two samples.

Type specimens: Holotype (MPEG.NEM 000062) and 4 paratypes (MPEG.NEM 000063) are deposited in the Museu Paraense Emílio Goeldi (MPEG), Belém, Pará, Brazil.

Type locality: Caxiuanã National Forest (Floresta Nacional de Caxiuanã), Melgaço municipality, Pará, Brazil; $1^{\circ} 47^{\prime} 32 " \mathrm{~S} ; 51^{\circ} 26^{\prime} 03^{\prime \prime} \mathrm{E}$
Type host: Adelphobates galactonotus (Steindachner) (Amphibia: Anura: Dendrobatidae), orange colour morph.

Localisation in host: Lungs.

Prevalence and intensity: 61\%(11 of 18); $2.4(1-5)$.

Ety mology: The species is named after the species name of the type host.

Remarks. The new species is assigned to the genus Rhabdias due to the following morphological characters: inflated body cuticle, small buccal capsule, amphidelphic genital system with short transverse vagina and joined uteri, and based on its lung parasitism in an amphibian host.

By the possession of six distinct lips, $R$. galactonoti is similar to eight Neotropical Rhabdias spp. from anuran amphibians: $R$. androgyna, $R$. breviensis, $R$. fuelleborni, $R$. kuzmini, R. manantlanensis, $R$. peninsularis, $R$. savagei, and $R$. tobagoensis.

Rhabdias galactonoti differs from $R$. androgyna, since the latter has a larger body (up to $15.4 \mathrm{~mm}$ long in adult specimens), an extended cuticular swelling consisting of 


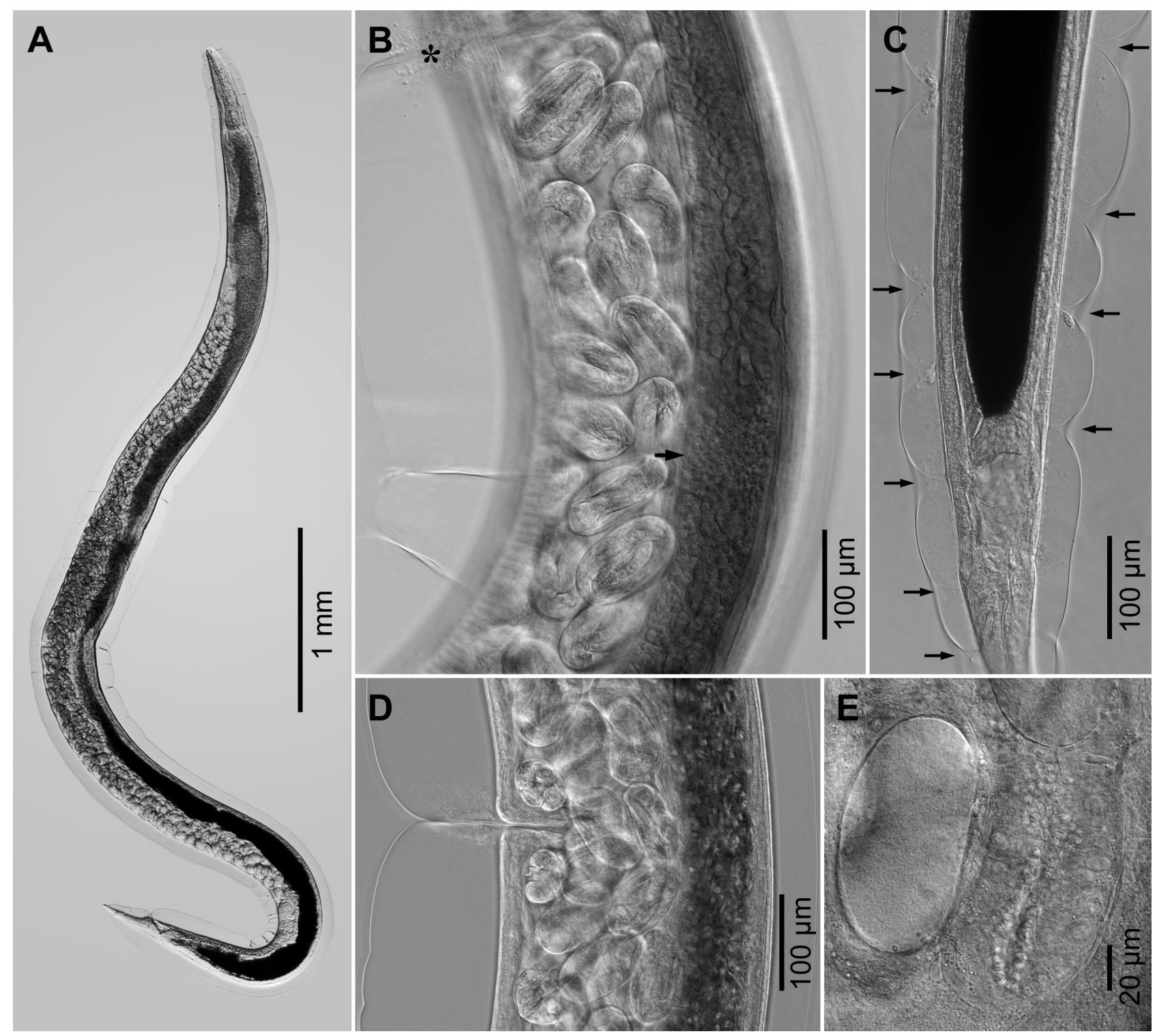

Fig. 2. Rhabdias galactonoti sp. n. from Adelphobates galactonotus (Steindachner), photomicrographs (paratypes). A - general view; $\mathbf{B}$ - mid-region of body, ventrolateral view showing vulva (asterisk) and testis zone in posterior syngonium (arrowhead); $\mathbf{C}-$ posterior part of body, dorsal view showing lateral pores (arrows); D - region of vulva, lateral view; E - U-bend of posterior seminal receptacle.

two layers at the anterior end, a particular shape of the anterior part of the body with a shoulder-like circular dilatation and a wider but shallower buccal capsule, 19-27 $\mu \mathrm{m}$ wide and 0.29-0.47 depth to width ratio (according to Kloss 1971, Kuzmin et al. 2015).

Rhabdias galactonoti differs from $R$. breviensis by having a longer but narrower body (in $R$. breviensis the body is 2.63-3.63 mm long and 370-543 $\mu \mathrm{m}$ wide near the vulva after Nascimento et al. 2013). Additionally, R. breviensis has a smaller buccal capsule, 4-9 $\mu \mathrm{m}$ deep and 7-13 $\mu \mathrm{m}$ wide, and the vulva is distinctly postequatorial: distance from anterior end to vulva corresponds to $65-71 \%$ of body length (Nascimento et al. 2013).

Rhabdias fuelleborni is similar to $R$. galactonoti in the relative length of the oesophagus and tail and in the position of the vulva. However, R. fuelleborni attains a larger body size than $R$. galactonoti, up to $10-12 \mathrm{~mm}$ (Travassos 1926) or $16.3 \mathrm{~mm}$ (Kloss 1971). Additionally, the lateral lips in $R$. gallactoniti are reduced, whereas in R. fuelleborni lips are similar in shape and size; the internal surface of the anterior part of the buccal capsule is folded in the former species and smooth in the latter; in R. fuelleborni the posterior part of the buccal capsule lacks the tooth-like projections, according to Kuzmin et al. (2015).

Rhabdias galactonoti is smaller than R. kuzmini, which is $14.2-19.2 \mathrm{~mm}$ long. In the latter species, a cuticular swelling is present mostly in the anterior and posterior parts, the lateral lips are modified to lateral pseudolabia, the buccal capsule is larger, 35-47 $\mu \mathrm{m}$ wide, and the vulva is mostly postequatorial (Martínez-Salazar and León-Règagnon 2007).

In contrast to $R$. galactonoti, $R$. manantlanensis is characterised by a body cuticle that is either not or only slightly inflated, a long and narrow vestibulum, a larger buccal capsule, 11-19 $\mu \mathrm{m}$ deep and 19-27 $\mu \mathrm{m}$ wide and completely surrounded by the anterior part of the oesophagus, as well 
Table 1. Metrical characters of Rhabdias galactonoti sp. n. from Adelphobates galactonotus. All measurements are in micrometres unless otherwise indicated.

\begin{tabular}{|c|c|c|c|}
\hline Characters & $\begin{array}{c}11 \text { specimens from orange } \\
\text { colour morph*, } \\
\text { mean (min.-max.) }\end{array}$ & $\begin{array}{l}7 \text { specimens from blue } \\
\text { colour morph, } \\
\text { mean (min.--max.) }\end{array}$ & $\begin{array}{c}\text { Entire sample, } \\
18 \text { specimens, } \\
\text { mean } \pm \mathrm{SD}\end{array}$ \\
\hline Body length (mm) & $5.6(4.9-6.2)$ & $6.9(6.3-7.2)$ & $6.1 \pm 0.8$ \\
\hline Body width at vulva & $236(189-268)$ & $247(227-270)$ & $240 \pm 25$ \\
\hline Body width at oesophago-intestinal junction & $142(123-176)$ & $160(142-169)$ & $149 \pm 15$ \\
\hline Buccal capsule maximum width & $15(14-17)$ & $18(16-20)$ & $16 \pm 2$ \\
\hline Buccal capsule depth & $11(10-12)$ & $11(11-12)$ & $11 \pm 1$ \\
\hline Buccal capsule depth/width ratio & $0.7(0.7-0.8)$ & $0.6(0.5-0.7)$ & $0.7 \pm 0.1$ \\
\hline Oesophagus length & $417(349-459)$ & $462(440-487)$ & $434 \pm 36$ \\
\hline Oesophagus length in $\%$ of body length & $7.5(6.8-8.2)$ & $6.7(6.3-7.0)$ & $7.2 \pm 0.6$ \\
\hline Width of oesophagus anterior end & $30(27-32)$ & $38(35-40)$ & $33 \pm 4$ \\
\hline Width of oesophagus anterior dilatation & $39(39-43)$ & $45(39-48)$ & $41 \pm 3$ \\
\hline Width of oesophagus posterior to dilatation & $32(31-37)$ & $37(35-39)$ & $34 \pm 3$ \\
\hline Width of oesophageal bulb & $64(59-73)$ & $77(70-84)$ & $69 \pm 8$ \\
\hline Distance from anterior end to nerve-ring & $170(149-184)$ & $195(173-226)$ & $180 \pm 18$ \\
\hline Distance from anterior end to vulva (mm) & $2.6(2.3-2.9)$ & $3.2(2.8-3.5)$ & $2.9 \pm 0.4$ \\
\hline Distance from anterior end to vulva in $\%$ of body length & $47.5(43.5-50.0)$ & $46.5(43.7-49.2)$ & $47 \pm 2$ \\
\hline Distance from anterior end to anterior bend of genital system & $875(593-1066)$ & $1189(1090-1490)$ & $997 \pm 201$ \\
\hline Distance from posterior bend of genital system to tail end & $832(733-1040)$ & $1069(830-1190)$ & $936 \pm 159$ \\
\hline Tail length & $277(229-333)$ & $321(298-353)$ & $240 \pm 37$ \\
\hline Tail length in $\%$ of body length & $5.0(3.8-6.5)$ & $4.6(4.2-5.0)$ & $4.9 \pm 0.7$ \\
\hline Distance from phasmids to tail end & $103(67-120)$ & $138(128-158)$ & $118 \pm 23$ \\
\hline
\end{tabular}

*_including type specimens.

as a shorter tail, 143-232 $\mu \mathrm{m}$ long, occupying $1.5-3.3 \%$ of body length (after Martínez-Salazar 2008) vs 3.8-6.5\% in R. galactonoti.

Based on the description of Martínez-Salazar et al. (2013), R. peninsularis can be recognised as distinct from $R$. galactonoti by a cuticular inflation that is mainly restricted to the anterior and posterior parts, a shorter vestibulum and a wide lumen of the buccal capsule. While the body length is similar in the two species, the oesophagus is shorter in R. peninsularis, representing 5.6-6.4\% of body length $v s 6.3-8.2 \%$ in $R$. galactonoti. In addition, the vulva in $R$. peninsularis is postequatorial, but mostly pre-equatorial in $R$. galactonoti.

Rhabdias galactonoti is larger than $R$. savagei, which, according to Bursey and Goldberg (2005), is 4.2-5.3 mm long. Additionally, the latter species lacks the dilatation in the anterior part of the oesophagus, and its oesophageal bulb is $43-52 \mu \mathrm{m}$ wide $v s 59-84 \mu \mathrm{m}$ in $R$. galactonoti; the position of the vulva in gravid $R$. savagei is post-equatorial.

Rhabdias tobagoensis is similar to $R$. galactonoti in body length but is much wider at mid-body, 408-476 $\mu \mathrm{m}$ (after Moravec and Kaiser 1995) vs 189-270 $\mu \mathrm{m}$. Lips in $R$. tobagoensis are more distinct in lateral view, and the anterior end is rounded and distinctly wider at the level of the buccal capsule than in $R$. galactonoti (present observations).

Rhabdias galactonoti has six small but distinct lips and by this character it can be distinguished from $R$. alabialis, $R$. elegans and $R$. paraensis. The latter three species have no lips and parasitise mostly bufonid hosts (Kuzmin et al. 2007, González and Hamann 2008, Santos et al. 2011). Details of the morphology of the anterior end are not known for $R$. hermaphrodita. This species, however, is larger than
$R$. galactonoti, up to $12.9 \mathrm{~mm}$ long, and parasitises bufonid hosts in southern Brazil (Kloss 1971, 1974), whereas $R$. galactonoti is described from a dendrobatid host endemic to eastern Amazonia.

Rhabdias stenocephala sp. n.

Figs. 3, 4

ZooBank number for species:

urn:Isid:zoobank.org:act:EE8EA365-9E8D-4170-9316-9309FEB763A0

Description. (Based on 11 type specimens, gravid hermaphrodites. Measurements are given for the holotype followed by the ranges for the type series in parentheses. Measurements of the whole studied sample are given in Table 2.)

Body elongated, gradually tapering from mid-length towards anterior and posterior extremities (Fig. 4A). Body length 7.7 (6.9-8.1) mm, width at vulva 414 (325-439), width at oesophago-intestinal junction 184 (164-188). Body cuticle inflated along entire body, with folds; no separated inflations observed in any part of body. Lateral pores present along whole body, lateral ducts in inflated cuticle funnel-shaped (Fig. 4B,E). Anteriormost part of body (excluding inflated cuticle) narrow, 45 (39-58) long and a maximum of 56 (48-61) wide in its posterior part, separated from remaining body by distinct constriction at level of anterior part of oesophagus (Figs. 3A,B, 4B). Posterior to constriction, body abruptly widening to 80 (65-80), then gradually widening posteriorly.

Six very small lips present on apical surface (Fig. 3D). Submedian lips elongated, overhanging edge of oral opening. Lateral lips reduced, located at distance from oral opening. Each lip with prominent internal labial papilla on inner edge. External labial papillae not observed. Amphi- 


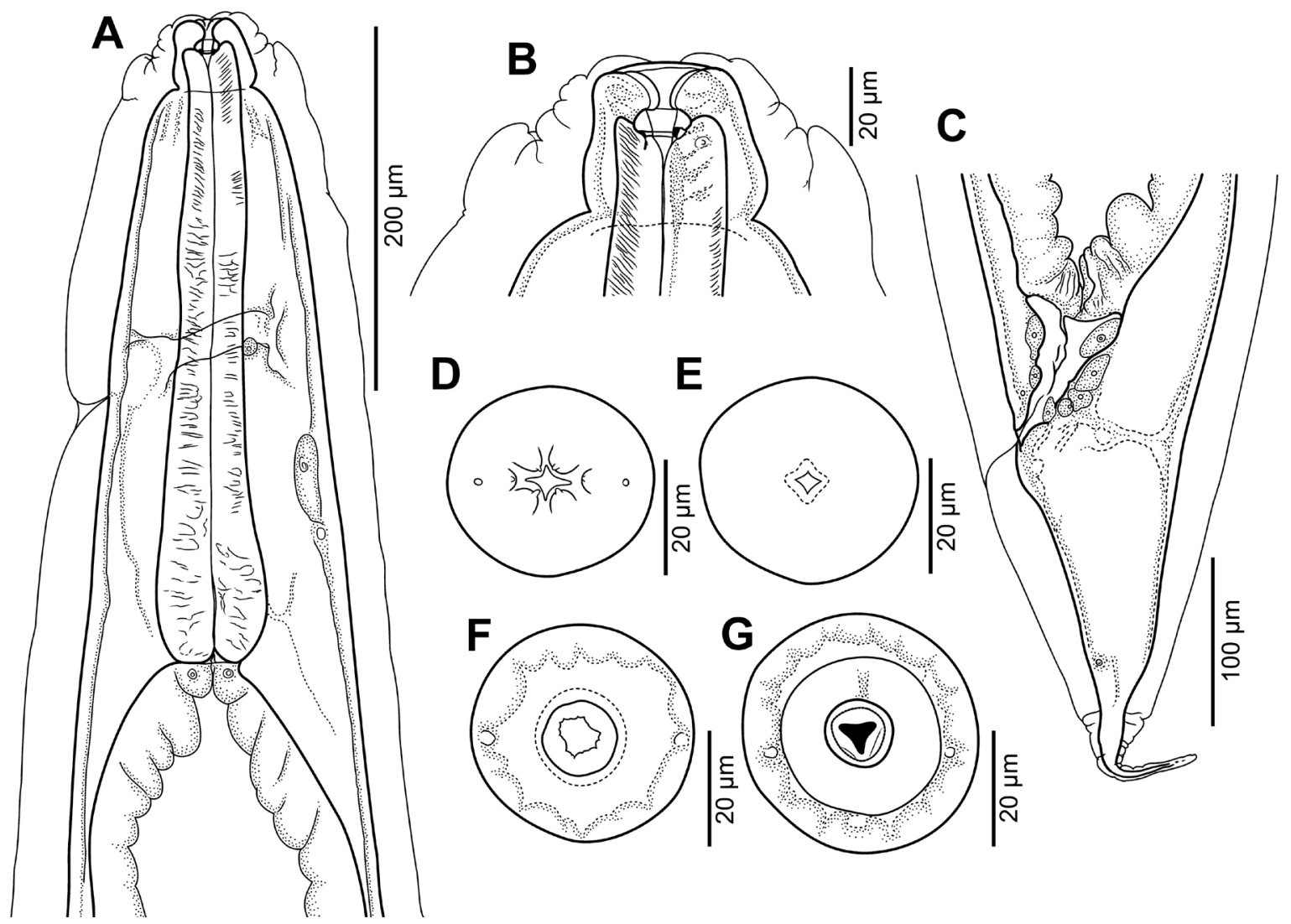

Fig. 3. Rhabdias stenocephala sp. n. from Leptodactylus pentadactylus (Laurenti), line drawings. A - anterior part of body, lateral view (holotype); B - anterior end, lateral view (holotype); C - posterior part of body, lateral view (holotype); D - anterior end of body, en face view; $\mathbf{E}$ - optical section through vestibulum; $\mathbf{F}$ - optical section through anterior part of buccal capsule; $\mathbf{G}$ - optical section through posterior part of buccal capsule.

dial openings indistinct. Vestibulum short, cuticularised, with rhomboid lumen in apical view (Fig. 3E). Buccal capsule doliiform, widest at mid-depth, with narrowing lumen (Fig. 3B). Buccal capsule walls separated into longer anterior part and ring-shaped posterior part. Wall of anterior part transparent; in apical view, outer surface of wall circular, inner surface irregularly folded (Fig. 3F). Posterior part denser, with circular thickening seen in apical view (Fig. 3G), connected to cuticularised oesophageal lumen. Depth of buccal capsule 9 (8-11), including both anterior and posterior parts, maximum width $17(15-18)$; depth to width ratio $0.5(0.5-0.7)$.

Oesophagus 410 (385-442) long [5.3\% (5.0-6.1\%) of body length], generally club-shaped (Fig. 3A), its anterior end at level of buccal capsule mid-length (Fig. 3B). Slight dilatation present in anterior part of oesophagus, at posterior part of its anterior third. Width of oesophagus at anterior end 31 (30-34), maximum width of anterior dilatation 45 (40-47). Posterior to dilatation, oesophagus 41 (34-41) wide, then gradually widening to oval-shaped posterior bulb, 71 (60-74) wide. Nerve-ring surrounding oesophagus posterior to its anterior dilatation, at 202 (192-225) from anterior end, this distance corresponding to $49 \%$ (47-53\%) of oesophagus length. Excretory pore observed in most specimens (Fig. 3A), at 245 (245-273) from anterior end. Excretory duct narrow, straight, poorly visible. Excretory glands absent.
Intestine narrow at its junction with oesophagus, abruptly widening posteriorly (Figs 3A, 4A). One or two coelomocytes visible posterior to oesophago-intestinal junction on ventral side of body. Rectum funnel-shaped, prominently cuticularised (Fig. 3C).

Genital system amphidelphic, typical of genus. Vulva postequatorial, located at $4.1 \mathrm{~mm}(3.5-4.4 \mathrm{~mm})$ from anterior end [53\% (51-55\%) of body length]. Lips of vulva slightly salient (Fig. 4D). Vagina short, transverse, cuticularised. Uteri joined, sac-like, thin-walled, elongated, filled with numerous $(>100)$ eggs. Most eggs containing fully-developed embryos. Egg size 112-132 × 58-72 ( $\mathrm{N}=10$, measured in uteri of holotype). Both syngonia U-bent in opposite directions at level of seminal receptacles. Anterior bend located at 1063 (814-1250) from anterior end, posterior bend at 623 (574-846) from posterior end. In bent areas, several additional loops usually present, more often in anterior syngonium. Testis zone observed in at least one of syngonia (Fig. 4C). Proximal ends of syngonia narrow, rounded, overlapping vulva.

Tail conical, gradually tapering posteriorly, somewhat dilated at level of phasmids (Fig. 3C). Slight elevation of body wall usually present on ventral side posterior to anus. Tail length 301 (266-339), or 3.9\% (3.3-4.2\%) of body length. Cuticular inflation not reaching tail tip. Phasmids located at about mid-length of tail (Fig. 4E), at 147 (120-173) from tail end. 


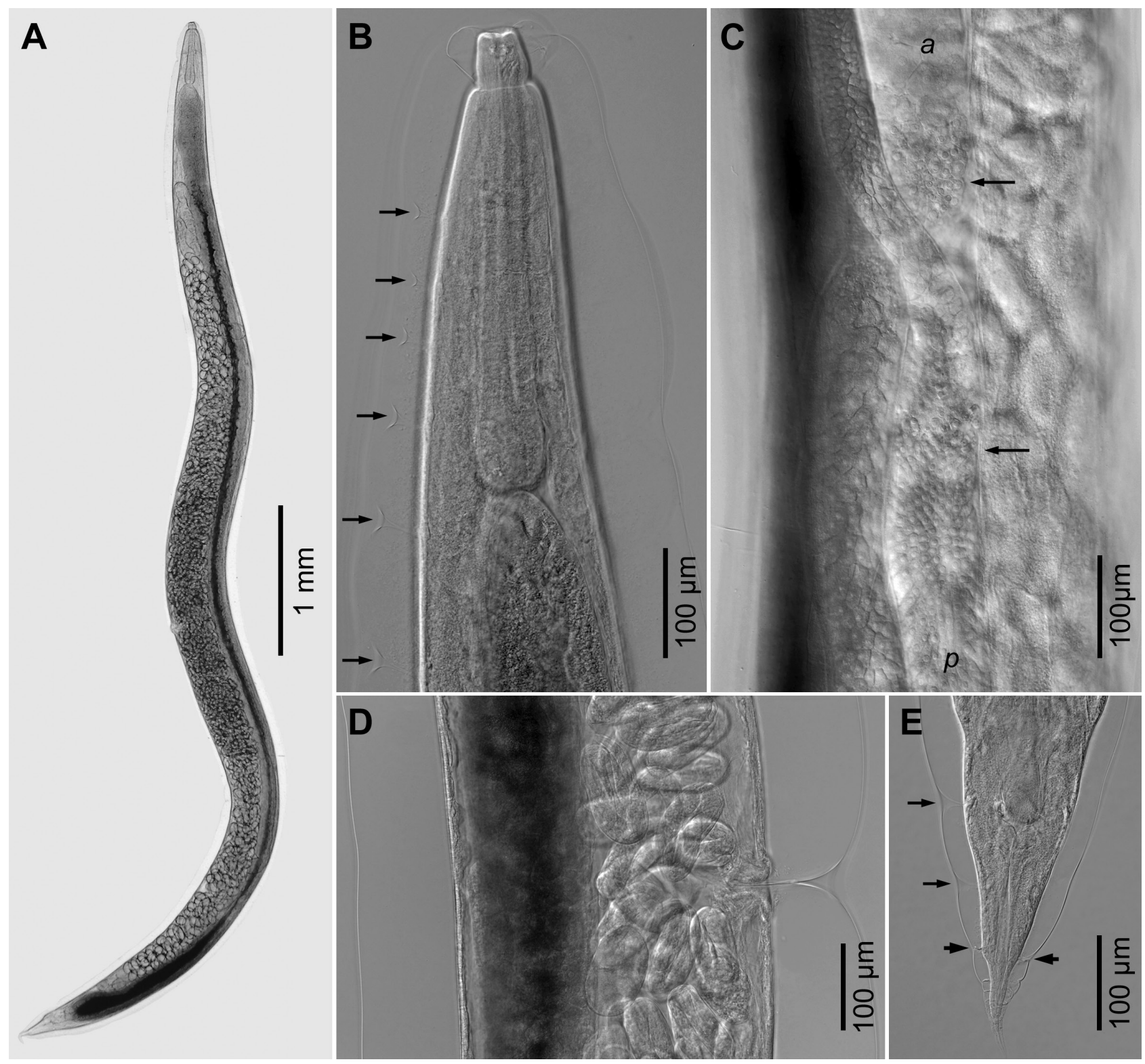

Fig. 4. Rhabdias stenocephala sp. n. from Leptodactylus pentadactylus (Laurenti), photomicrographs (paratypes). A - general view; $\mathbf{B}$ - anterior part of body, dorsolateral view showing lateral pores (arrows); $\mathbf{C}$ - mid-region of body, dorsolateral view showing anterior (a) and posterior $(p)$ syngonia with testis zones (arrows); D - region of vulva, lateral view; $\mathbf{E}$ - posterior end, dorsal view showing phasmids (arrowheads) and lateral pores (arrows).

Variability. Body length and related metrical characters in specimens from L. paraensis were somewhat smaller than in specimens from L. pentadactylus, though the ranges of each metrical character overlapped (Table 2). The dimensions of the buccal capsule, anterior constricted part of the body and distance from phasmids to tail end were almost identical in the two samples. Qualitative characters in specimens from the two host species were found not to be different.

Immature specimens of $R$. stenocephala were not recovered in the present study.

Type specimens: Holotype (MPEG.NEM 000064) and 10 paratypes (MPEG.NEM 000065) are deposited in in the Museu Paraense Emílio Goeldi (MPEG), Belém, Pará, Brazil.

Type locality: Caxiuanã National Forest (Floresta Nacional de Caxiuanã), Melgaço municipality, Pará, Brazil;

\section{$1^{\circ} 47^{\prime} 32^{\prime \prime} \mathrm{S} ; 51^{\circ} 26^{\prime} 03^{\prime \prime E}$}

Type host: Leptodactylus pentadactylus (Laurenti) (Amphibia: Anura: Leptodactylidae).

Other host: L. paraensis (Heyer) (Amphibia: Anura: Leptodactylidae).

Localisation in host: Lungs.

Prevalence and intensity of infection: L. pentadactylus - prevalence $25 \%$ ( 1 of 4 ), intensity $11 ; L$. paraensis - prevalence $45 \%$ (5 of 11), intensity $3.2(1-5)$.

E t y m olog y: The name 'stenocephala' is given to the species due to its characteristically narrowed anterior end.

Remarks. Rhabdias stenocephala is assigned to the genus Rhabdias due to the following morphological characters: inflated body cuticle, small buccal capsule, amphidelphic genital system with short transverse vagina and 
Table 2. Metrical characters of Rhabdias stenocephala sp. n. from Leptodactylus spp. All measurements are in micrometres unless otherwise indicated.

\begin{tabular}{|c|c|c|c|}
\hline Characters & $\begin{array}{l}11 \text { specimens* } \\
\text { from } L . \text { pentadactylus, } \\
\text { mean (min.-max.) }\end{array}$ & $\begin{array}{l}15 \text { specimens } \\
\text { from } L \text {. paraensis, } \\
\text { mean (min.--max.) }\end{array}$ & $\begin{array}{l}\text { Entire sample, } \\
26 \text { specimens, } \\
\text { mean } \pm \mathrm{SD}\end{array}$ \\
\hline Body length (mm) & $7.7(6.9-8.1)$ & $6.9(4.5-7.9)$ & $7.2 \pm 0.8$ \\
\hline Body width at vulva & $406(325-439)$ & $348(284-396)$ & $373 \pm 43$ \\
\hline Body width at oesophago-intestinal junction & $175(164-188)$ & $163(142-182)$ & $168 \pm 11$ \\
\hline Length of anterior constricted part & $48(39-58)$ & $49(38-55)$ & $48 \pm 5$ \\
\hline Maximum width of anterior constricted part & $55(48-61)$ & $51(46-60)$ & $53 \pm 4$ \\
\hline Body width posterior to constriction & $75(65-80)$ & $72(61-88)$ & $73 \pm 7$ \\
\hline Buccal capsule maximum width & $17(15-18)$ & $17(16-18)$ & $17 \pm 1$ \\
\hline Buccal capsule depth & $9.5(8.0-11.0)$ & $9.5(9.0-10.0)$ & $9.5 \pm 0.6$ \\
\hline Buccal capsule depth/width ratio & $0.6(0.5-0.7)$ & $0.6(0.5-0.6)$ & $0.6 \pm 0.04$ \\
\hline Oesophagus length & $414(385-442)$ & $405(354-453)$ & $409 \pm 23$ \\
\hline Oesophagus length in $\%$ of body length & $5.4(5.0-6.1)$ & $6.0(5.4-7.8)$ & $5.7 \pm 0.7$ \\
\hline Width of oesophagus anterior end & $31(30-34)$ & $30(26-35)$ & $31 \pm 2$ \\
\hline Width of oesophagus anterior dilatation & $44(40-47)$ & $42(36-47)$ & $43 \pm 3$ \\
\hline Width of oesophagus posterior to dilatation & $39(34-41)$ & $37(30-42)$ & $38 \pm 3$ \\
\hline Width of oesophageal bulb & $69(60-74)$ & $66(65-83)$ & $68 \pm 7$ \\
\hline Distance from anterior end to nerve-ring & $208(192-225)$ & $194(168-214)$ & $200 \pm 13$ \\
\hline Distance from anterior end to vulva (mm) & $4.1(3.5-4.4)$ & $3.7(2.4-4.1)$ & $3.9 \pm 0.4$ \\
\hline Distance from anterior end to vulva in \% of body length & $53(51-55)$ & $54(48-59)$ & $54 \pm 2$ \\
\hline Distance from anterior end to anterior bend of genital system & $1010(814-1250)$ & $1036(600-1387)$ & $1025 \pm 191$ \\
\hline Distance from posterior bend of genital system to tail end & $685(574-846)$ & $622(491-794)$ & $649 \pm 100$ \\
\hline Tail length & $299(266-339)$ & $283(234-345)$ & $290 \pm 28$ \\
\hline Tail length in \% of body length & $3.9(3.3-4.2)$ & $4.1(3.3-5.7)$ & $4.1 \pm 0.6$ \\
\hline Distance from phasmids to tail end & $145(120-173)$ & $145(112-177)$ & $145 \pm 17$ \\
\hline
\end{tabular}

*-type series.

joined uteri; and due to its lung parasitism in amphibian hosts.

The new species differs from all known Rhabdias spp. parasitising Neotropical anurans, as well as from any other species of the genus, in the specific shape of its anterior end: narrow anterior part separated from the remaining body by a distinct constriction. With regard to other morphological characters, $R$. stenocephala is similar to several mid-sized (body 4-8 mm long) Neotropical species possessing distinct lips and parasitising anuran hosts: $R$. manantlanensis, $R$. peninsularis, $R$. savagei, $R$. tobagoensis and $R$. galactonoti sp.n.

Rhabdias stenocephala differs from $R$. manantlanensis by a smaller buccal capsule, which is 19-27 $\mu \mathrm{m}$ wide in the latter species (Martínez-Salazar 2008); additionally, $R$. manantlanensis has a mostly pre-equatorial vulva and shorter tail, representing 1.5-3.3\% of body length (Martínez-Salazar 2008) vs 3.3-5.7\% in R. stenocephala.

In contrast to $R$. stenocephala, the cuticular inflation in $R$. peninsularis is prominent mostly in the anterior and posterior parts but does reach the tip of the tail. Furthermore, $R$. peninsularis has a short vestibulum and a differently structured buccal capsule: almost spherical, thick-walled, with wide, not cylindrical lumen (Martínez-Salazar et al. 2013). Eggs in R. stenocephala are somewhat larger than in $R$. peninsularis: $112-132 \mu \mathrm{m} \times 58-72 \mu \mathrm{m} v s 85-104 \mu \mathrm{m} \times$ $42-54 \mu \mathrm{m}$. The tail in $R$. peninsularis is short $(139-213 \mu \mathrm{m}$ long), the tail tip is covered by the inflated cuticle (Martínez-Salazar et al. 2013), whereas in R. stenocephala the tail is longer (234-345 $\mu \mathrm{m}$ long) and the cuticular swelling does not reach the tail tip.
Rhabdias stenocephala is somewhat larger than $R$. savagei, which is $4.2-5.3 \mathrm{~mm}$ long according to Bursey and Goldberg (2005); the latter species possesses a larger buccal capsule, 18-24 $\mu \mathrm{m}$ wide, and narrower oesophageal bulb, $43-52 \mu \mathrm{m}$ wide. The excretory pore in $R$. savagei is situated at the level of the oesophageal bulb, 336-415 $\mu \mathrm{m}$ from the anterior end, whereas in $R$. stenocephala the excretory pore is located just posterior to the mid-length of the oesophagus, $214-273 \mu \mathrm{m}$ from the anterior end.

Rhabdias stenocephala differs from $R$. tobagoensis by having a narrower buccal capsule (15-18 $\mu \mathrm{m} v s$ 18-21 $\mu \mathrm{m}$ wide) and small, less conspicuous lips; lips are distinct in the latter species (Moravec and Kaiser 1995).

Smaller lips also separate $R$. stenocephala from Rhabdias galactonoti; in addition, the latter species has a mostly pre-equatorial vulva and a narrower body at the level of the vulva, 189-270 $\mu \mathrm{m} v s$ 284-439 $\mu \mathrm{m}$ in $R$. stenocephala (Tables 1, 2).

\section{DISCUSSION}

Rhabdias galactonoti $\mathrm{sp} . \mathrm{n}$. and R. stenocephala sp. n. are the $16^{\text {th }}$ and $17^{\text {th }}$ nominal species of Rhabdias known from amphibian hosts in the Neotropical Realm. However, $R$. mucronata and $R$. truncata were inadequately described based on juveniles only and are considered species inquirendae (Bursey et al. 2003, Martínez-Salazar et al. 2009, 2013). Therefore, the number of valid species of the genus parasitising amphibians of the Neotropics is still 15 , including the two new species described in the present paper. 
In the Neotropics, Rhabdias spp. parasitise amphibian hosts from various families. Eight species (R. alabialis, $R$. androgyna, $R$. elegans, $R$. fuelleborni, $R$. hermaphrodita, $R$. kuzmini, $R$. paraensis, $R$. pseudosphaerocephala) are known exclusively or mostly from Bufonidae, others are from hosts belonging to Leptodactylidae ( $R$. breviensis), Craugastoridae (R. manantlanensis, $R$. tobagoensis), Hylidae (R. peninsularis), Ranidae, Craugastoridae and Leptodactylidae (R. savagei) (Bursey and Brooks 2010; Kuzmin et al. 2015). Rhabdias galactonoti is the first species of the genus described from Dendrobatidae; $R$. stenocephala is the second species specific to Leptodactylidae. Dendrobatid and leptodactylid frogs are diurnal, showing complex behaviour patterns; some species display parental care and diverse reproductive strategies (Heyer 1969, Duellman 1992, Brust 1993, Caldwell 1997). Interestingly, A. galactonotus is a generally terrestrial species, in contrast to other mostly arboreal Dendrobatidae (Duellman 1992). This feature might have facilitated its association with a specific Rhabdias parasite.

The morphological differences documented in the two samples of $R$. galactonoti from spatially separated populations of orange and blue colour morphs of the host (see Table 2) might demonstrate the speciation process caused by the isolation and/or specialisation in a particular host morph. However, the studied samples were too small to reveal statistically significant differences. In our opinion, further morphological studies combined with molecular investigations may clarify the intraspecific structure of the species or identify cryptic species within the R. galactonoti complex.

Studied samples of $R$. stenocephala from two hosts, L. pentadactylus and L. paraensis, appeared to be similar both in metrical and qualitative characters. Populations of the two hosts occur in the same habitats of the study area, and the parasite is apparently shared by them. Presently it is not clear, whether one of the host species is more important for the persistence of the parasite population, since both host samples were rather small, 4 and 11 specimens, correspondingly.

The wide host range reported for some Rhabdias spp. in the Neotropics is presumed, in some cases, to be a result of incorrect species identification (Martínez-Salazar et al. 2009, Kuzmin et al. 2015). Thorough morphological studies and further characters revealed by them might improve species diagnostics and make identifications more reliable. Detailed examination of the buccal capsule may provide additional diagnostic characters for Rhabdias spp. (Lhermitte-Vallarino et al. 2010, Kuzmin et al. 2015). For example, in the presently described two Rhabdias species, the inner surface of the anterior part of the buccal capsule bears similar folds, which differentiates them from $R$. paraensis and R. fuelleborni, in both of which the inner surface of the anterior part of the buccal capsule is smooth (Kuzmin et al. 2015, Melo et al. 2016). In our opinion, detailed studies of the morphology of the anterior end are essential for further investigations of Rhabdias spp. in the Neotropical Realm as well as worldwide.

Acknowledgements. Financial support for this study was provided by the PROPESP/PPGBAIP/UFPA, PPGZOO/UFPA/ MPEGP; CAPES Foundation, the Ministry of Education of Brazil (grant CAPES-Parasitologia Básica/2010), and the National Council for Scientific and Technological Development (CNPq) (grants SISBiota 2010-Sistema Nacional de Pesquisa em Biodiversidade, PVE CAPES/CNPq A_033/2013; Doctorate Scholarship of HFSF and Research grant of productivity of JNS).

\section{REFERENCES}

Anderson R.C. 2000: Nematode Parasites of Vertebrates. Their Development and Transmission. Second Edition. CABI Publishing, Wallingford, $650 \mathrm{pp}$.

BAKER M.R. 1979: The free-living and parasitic development of Rhabdias spp. (Nematoda: Rhabdiasidae) in amphibians. Can. J. Zool. 57: 161-178.

Bursey C.R., Brooks D.R. 2010: Nematode parasites of 41 anuran species from the Area de Conservación Guanacaste, Costa Rica. Comp. Parasitol. 77: 221-231.

Bursey C.R., Goldberg S.R. 2005: New species of Oswaldocruzia (Nematoda: Molineoidae), new species of Rhabdias (Nematoda: Rhabdiasidae), and other helminths in Rana cf. forreri (Anura: Ranidae) from Costa Rica. J. Parasitol. 91: 600-605.

Bursey C.R., Goldberg S.R., Telford S.R., Jr. 2003: Rhabdias anolis n. sp. (Nematoda: Rhabdiasidae) from the lizard, Anolis frenatus (Sauria: Polychrotidae), from Panama. J. Parasitol. 89: 113-117.

Brust D.G. 1993: Maternal brood care by Dendrobates pumilio: a frog that feeds its young. J. Herpetol. 27: 96-98.

Caldwell J. 1997: Pair bonding in spotted poison frogs. Nature 385: 211.

Duellman W.E. 1992: Biology of Amphibians. The John Hopkins University Press, Baltimore, Maryland, $670 \mathrm{pp}$.

Frost D.R. 2016: Amphibian Species of the World: an Online Reference. Version 6.0. Electronic Database, http://research.amnh. org/herpetology/amphibia/index.php, American Museum of Natural History, New York, 03/2016.
González C.E., Hamann M.I. 2008: Nematode parasites of two anuran species Rhinella schneideri (Bufonidae) and Scinax acuminatus (Hylidae) from Corrientes, Argentina. Rev. Biol. Trop. 56: 2147-2161.

Heyer W.R. 1969: The adaptive ecology of the species groups of the genus Leptodactylus (Amphibia, Leptodactylidae). Evolution 23: 421-428.

Hoogmoed M.S., Avila-Pires T.C.S. 2012: Inventory of color polymorphism in populations of Dendrobates galactonotus (Anura: Dendrobatidae), a poison frog endemic to Brazil. Phyllomedusa 11: 95-115.

Kloss G.R. 1971: Alguns Rhabdias de Bufo no Brasil. Pap. Avulsos Zool. (São Paulo) 24: 1-52.

KLoss G.R. 1974: Rhabdias (Nematoda, Rhabditoidea) from the marinus group of Bufo. A study of sibling species. Arq. Zool. (São Paulo) 25: 61-120.

Kuzmin Y., Du Preez L.H., Junker K. 2015: Some nematodes of the genus Rhabdias Stiles et Hassall, 1905 (Nematoda: Rhabdiasidae) parasitising amphibians in French Guiana. Folia Parasitol. 62: 031.

Kuzmin Y., Tкасн V.V. 2015: Rhabdias. World Wide Web electronic publication, http://izan.kiev.ua/ppages/rhabdias, 05/2015.

Kuzmin Y., Ткасн V.V., Brooks D.R. 2007: Two new species of Rhabdias (Nematoda: Rhabdiasidae) from the marine toad, Bufo marinus (L.) (Lissamphibia: Anura: Bufonidae) in Central America. J. Parasitol. 93: 159-165. 
LANGFORD G.J., JANOVY J., JR. 2009: Comparative life cycles and life histories of North American Rhabdias spp. (Nematoda: Rhabdiaisidae): lungworms from snakes and anurans. J. Parasitol. 95: 1145-1155.

Lhermitte-Vallarino N., Barbuto M., Junker K., Boistel R., Bain O. 2010: Rhabdias (Nematoda: Rhabdiasidae) from Chamaeleonidae (Sauria): two new species from Trioceros ellio$t i$ in east Africa and one from Brookesia superciliaris in Madagascar. Parasite 17: 91-105.

Martínez-Salazar E.A. 2008: A new rhabdiasid species from Craugastor occidentalis (Anura: Brachycephalidae) from Sierra de Manantlán, Jalisco, Mexico. Rev. Mex. Biodiv. 79: 81-89.

Martínez-Salazar E.A., Falcón-Ordaz J., González-Bernal E., Parra-Olea G., Pérez-Ponce De León G. 2013 Helminth parasites of Pseudacris hypochondriaca (Anura: Hylidae) from Baja California, Mexico, with the description of two new species of nematodes. J. Parasitol. 99: 1077-1085

Martínez-Salazar E.A., León-RÈGagnon V. 2007: New species of Rhabdias (Nematoda: Rhabdiasidae) from Bufo occidentalis (Anura: Bufonidae) from Sierra Madre del Sur, Mexico. J. Parasitol. 93: 1171-1177.

Martínez-Salazar E.A., Pérez-Ponce De León G., Parra Olea G. 2009: Primer registro del género Rhabdias (Nematoda: Rhabdiasidae), endoparásito de Scinax staufferi (Anura: Hylidae) en México. Rev. Mex. Biodiv. 80: 861-865.
Melo F.T.V., Nascimento L.C.S., Macedo L.C., Santos J.N., KuZMin Y. 2016: The morphology of free-living stages and immature parasites of Rhabdias paraensis (Nematoda: Rhabdiasidae), a parasite of Rhinella marina (Anura: Bufonidae) in Brazil. Acta Parasitol. 61: 42-51.

Moravec F., Kaiser H. 1995: Helminth parasites from West Indian frogs, with descriptions of two new species. Carib. J. Sci. 31: $252-268$.

Nascimento L.C., Gonçalves E.C., Melo F.T., Giese E.G., Furtado A.P., Santos J.N 2013: Description of Rhabdias breviensis n. sp. (Rhabditoidea: Rhabdiasidae) in two Neotropical frog species. Syst. Parasitol. 86: 69-75.

de Sá R.O., Grant T., Camargo A., Heyer W. R., Ponssa M. L., Stanley E. 2014: Systematics of the Neotropical genus Leptodactylus Fitzinger, 1826 (Anura: Leptodactylidae): phylogeny, the relevance of non-molecular evidence, and species accounts. South American J. Herpetol 9 (Special Issue 1): S1-S128.

Santos J.N., Melo F.T.V., Nascimento L.C.S., Nascimento D.E.B., Giese E.G., Furtado A.P. 2011: Rhabdias paraensis sp. n.: a parasite of the lungs of Rhinella marina (Amphibia: Bufonidae) from Brazilian Amazonia. Mem. Inst. Oswaldo Cruz 106: 433-440.

Travassos L. 1926: Entwicklung des Rhabdias fülleborni n. sp. Arch. Schiffs Tropen-Hyg. 30: 594-602.

Cite this article as: Kuzmin Y., Melo F.T.V., Silva Filho H.F., Santos J.N. 2016: Two new species of Rhabdias Stiles et Hassall, 1905 (Nematoda: Rhabdiasidae) from anuran amphibians in Pará, Brazil. Folia Parasitol. 63: 015. 